\title{
UN EJEMPLO DE URBANISMO NEOCLÁSICO. LA PLAZA DEL BUEN JESÚS DE LUGO
}

\author{
por
}

ADOLFO DE ABEL VILELA

La renovación estética desarrollada por los ilustrados en el último tercio del siglo XVIII, se produce, con mejores resultados que en el resto de las artes, en la arquitectura y el urbanismo. Por una parte se van a introducir mejoras en la habitabilidad de las viviendas y del ornato público, y por otra se crearán nuevas plazas con criterios de comodidad y utilidad colectiva.

Se inicia el declive del urbanismo medieval y la aparición del espíritu renovador del siglo XIX, que en Lugo se desarrollará en los reinados de Isabel II y de su hijo Alfonso XII, es decir, en los períodos Isabelino y de la Restauración.

Chueca Goitia, dice que en ese momento comienzan los balbuceos del arte romántico y afirma que el neoclasicismo es sólo un fantasma. No existe más que un arte barroco que termina sus días en un clasicismo cansado, a la vez que un arte barroco comienza los suyos liricamente enamorado de la antigüedad clásica, que nada tiene que ver con el moribundo clasicismo académico ${ }^{1}$. Renace así un nuevo clasicismo, distinto al del siglo XVI, gracias a las informaciones dadas por los hallazgos arqueológicos de Herculano (1719) y Pompeya (1748).

El debate dieciochesco sobre la ciudad, girará, por una parte en torno a las teorías de Laugier, y por otra a las de Pierre Patte. El primero, en sus reflexiones sobre la arquitectura, nos da una definición sobre la estética

\footnotetext{
' Javier Cenicacelaya e Iñigo Saloña. Neoclasicismo, dilemas y equilibrio. En Arquitectura Neoclásica en el País Vasco. Bilbao, 1990, p. 11.
}

"CUADERNOS DE ESTUDIOS GALLEGOS", Tomo XLI, Fascículo 106, Santiago 1993-94. 
de la ciudad. Opina que se le debe considerar como una floresta. En lugar de la regularidad y el orden, busca una cierta idea de irregularidad y caos. Con esta comparación quiere contraponer la regularidad y racionalidad humana al capricho de la naturaleza. En realidad es la ideología romántica de lo pintoresco, que en jardinería contrapone la espontaneidad de la naturaleza a la artificiosa geometría de los jardines barrocos.

El plano de una ciudad debía ser diseñado de suerte que la magnificencia del conjunto se subdividiese o fragmentase en infinidad de bellezas de detalle, todas ellas diferentes. De esta forma el viandante no volvería a encontrar casi nunca los mismos objetos, que al recorrer la ciudad de un extremo a otro fuese posible descubrir en cada barrio algo nuevo, singular $y$ atrayente, que exista un orden y, sin embargo, que se de una especie de confusión; que todo aparezca alineado, pero sin monotonía, y que de toda una multitud de partes regulares resulte en total una cierta idea de irregularidad y de caos, cosa que conviene a las grandes ciudades².

Su pretensión, pues, es conciliar lo ya existente con lo nuevo, hacer presente el contraste entre un urbanismo medieval, calles estrechas y laberínticas, plazas irregulares, incluso la sorpresa y teatralidad del urbanismo barroco, con otro racionalista. De acuerdo con estas características, Lugo sería una ciudad en la que el itinerario urbano se convierte en una constante variedad de sensaciones estéticas.

La Encyclopêdie, señala como elemento necesario, para que una ciudad sea bella, que el trazado de sus calles se haga en damero o hipodámico, que en las confluencias se abran plazas y que estas se decoren de manera que se garantice la uniformidad de las fachadas de los hotels y de las casas que forman esas plazas ${ }^{3}$.

La remodelación de la plaza del Buen Jesús (1770-1788), que supone el inicio del urbanismo moderno en Lugo, fue obra de José de Elexalde, en lo arquitectónico y de Miguel Ferro Caaveiro y Alexos Frieiro en lo urbanístico. La harán siguiendo estos criterios urbanísticos y estéticos, capaces de producir una diversidad de itinerarios, pero también de acuerdo con los gustos y pretensiones de una sociedad que evoluciona hacia una burguesía comerciante que paulatinamente va a sustituir a la aristocracia.

\footnotetext{
${ }^{2}$ Bardet, G. Naissance et méconnaissance de l'urbanisme. París, 1951, p. 335.

${ }^{3}$ Voz: Ville. Dictionnaire raisonné des sciences, des arts et des méiers. Livorno, 1775. Vol. XVII, p. 269.
}

"CUADERNOS DE ESTUDIOS GALLEGOS", Tomo XLI, Fascículo 106, Santiago 1993-94. 


\section{LAS NOVEDADES ARQUITECTÓNICAS}

El rechazo de la arquitectura tardo barroca o rococó que dará lugar a una desornamentación de los muros, haciéndolos sobrios, volviéndolos al primer barroco romano, da lugar a una nueva estética, surgida, entre otras razones, de la influencia enciclopedista, que llega a Galicia a través de los ingenieros militares. Con ellos se introduce la noción de confort, mejorando la habitabilidad de las casas gracias a su distribución. La idea palladiana de que cada parte del edificio tenga su reflejo en el exterior, será una más de las características a tener en cuenta al analizar la arquitectura de este período.

La tipología de edificio de este momento va a ser distinto al del barroco pero se acercará al del período isabelino. Se da primacia a la comididad, con una buena distribución y construcción, reducción de la altura y tamaño de las habitaciones para hacerlas más calientes, utilización del vano rasgado o de puerta ventana para facilitar la entrada de mayor cantidad de luz y sol, y empleo de escaleras más funcionales reduciendo el hueco y su papel representativo.

También se incorporan nuevos sistemas constructivos. Se recuperan los tabiques de tambor, una armación de madera y barrotillo, enlucido con mortero de cal, que permite una compartimentación del espacio más acorde con las necesidades, reduciendo las cargas y el espesor de los muros de separación. El mismo sistema se utilizará para el cielo raso.

Aunque en apariencia las casas conforman una unidad, el edificio del lado $\mathbf{S}$ lo componen tres viviendas y el del lado $\mathbf{N}$ otras tres o cuatro. Ambos presentan hoy alteraciones, como la transformación de los tragaluces de la planta baja en vanos rasgados, o el añadido de balcones en voladizo a los que habían sido diseñados sin él.

A pesar de estas alteraciones, gracias a la conservación de algunos elementos, se puede deducir la estructura externa original. Parece que el modelo obedecía a un edificio de tres plantas, baja, alta, segunda o principal y aprovechamiento del bajo cubierta con buhardillas. El parcelario de cada vivienda permitiría un desarrollo de dos vanos por planta. En la inferior el correspondiente a la puerta de entrada y un tragaluz. En el primero dos ventanas con antepecho, y en el segundo un vano rasgado con acceso a un balcón muy volado y otro con barandal a nivel de fachada.

En el edificio del lado $\mathbf{S}$, podemos ver como el balcón está en el mismo eje que la puerta de entrada, posiblemente para su resguardo de la lluvia, colocando en el entrepaño un tragaluz ovalado, forma que ya nos sitúa en 
el romanticismo, lo que nos hace suponer que su construcción es posterior al del lado $\mathbf{N}$. Hay otro detalle que conecta con los edificios clasicistas que se harán en la primera mitad del siglo XIX. Se trata de la cornisa que se coloca sobre el dintel del tragaluz que al mismo tiempo sirve de solera a la ventana del cuerpo superior. El aumento de su anchura, y el rasgado del vano, dará lugar al balcón en voladizo.

Los vanos del primer cuerpo serán de dintel recto o curvo, con orejeras en la parte superior, reminiscencia del barroco. En ellos se trata de imitar, por razones de equilibrio compositivo, un rasgado cegado, mediante la prolongación del jambaje que delimita un cajeado en el pretil de la ventana. Con este recurso óptico se consigue dilatar la altura de la entreplanta y aligerar visualmente el muro, restando importancia al conjunto. De esta forma se destaca la más alta que será la principal.

Hay correspondencia de vanos, lo que da una cierta racionalidad a la composición general de la fachada, aunque su regularidad se rompe con los balcones en voladizo, cuya solera descansa sobre tres grandes ménsulas, únicos elementos con decoración. Su ausencia está en consonancia con las teorías del veneciano Lodoli, que defendía la funcionalidad de los edificios. El adorno, por ser accesorio a la función, es supérfluo.

En el período isabelino, esta decoración se hará con elementos arquitectónicos clásicos, como unos tacos o triglifos que a modo de ménsula van a figurar entre el dintel del vano y el resalte o pequeño voladizo que servirá de base al superior.

Los hierros de protección de los vanos rasgados, o los barandales de los balcones, serán como en el barroco, balaustres de bellota, predominio de la verticalidad, mientras que después, serán de cinta forjada a base de círculos en cuya intersección se coloca una flor. Se introduce la curva.

\section{LAS CASAS DEL CABILDO}

El Cabildo catedralicio convence a varios particulares propietarios de algunas casas, de desigual importancia y apariencia estética, para que las derriben y las reedifiquen según los planos realizados por el maestro profesor de arquitectura y dibujante José de Elexalde.

La construcción de los edificios se hizo por fases. El Cabildo había cambiado una de las viejas casas que pertenecía a la capellanía de Biville, que hace esquina a la calle que va desde dicha Santa Iglesia al Pozo da Pinguela y Puerta Miñá, donde antes se hallaba la que fue de la citada

"CUADERNOS DE ESTUDIOS GALLEGOS", Tomo XLI, Fascículo 106, Santiago 1993-94. 
capilla $^{4}$, y otra en la que vivía Antonio Trigo. En la primavera de 1772, estaba concluida la primera, pero para poder construir la siguiente, surgían algunos problemas con la colindante, propiedad del abogado de los reales consejos don Antonio de Neira Quintana y Vaamonde.

El arcediano de Sarria, don Antonio Felipe Rodríguez, vicesecretario del deán y Cabildo, certificaba que en el auto capitular celebrado el día 5 de mayo de 1772, el arcediano de Neira había propuesto que en virtud de la comisión que tenía para la obra de la fachada de la catedral y construcción de casas citadas se le habían propuesto algunos reparos por parte del abogado don Pedro de Neira, que vive en la casa que dice junto a la última expresada, a la parte de abajo, y tiene otra terrena en el mismo sitio, manifestando algunos perjuicios que se le seguían de la citada fábrica, así de la parte de adelante, como de la de atrás; y que igualmente se le podían seguir al Cabildo y su fábrica en no construir la dicha casa con la simetría y conveniencia que ofrecía un armonioso ajuste con dicho don Pedro de Neira ${ }^{5}$.

Pasaron los dos al sitio acompañados del maestro José de Elexalde. Después de intercambiar sus opiniones convinieron amigablemente lo que se había de ejecutar materializado en documento el día 2 de junio, con la presencia de don Antonio Cosentino de Tejada, arcediano de Neira, don Antonio de Neira y su mujer doña Feliciana Mejía y Neira.

Según lo acordado, se derribaría la casa terrena que estaba en medio de la de éste y la del Cabildo que pretendía levantar, la cual se sacaría en escuadría por la parte que daba a la plazuela del Buen Jesús, en línea recta a la esquina de la casa que habitaba, imponiendo la condición de que la ha de alzar por atrás y por delante a correspondencia e igualdad de la que ya tiene hecha; que por la parte de atrás ha de dirigir la pared desde los dentellones que están en la medianil que divide la casa de dicho Cabildo de la de Marcos Picado, siguiéndola en derechura por debajo el miembro de la segunda ventana que en aquella parte tiene la en que vive dicho don Pedro, fijándola en la pared de esta en el sitio que para ello han rayado y señalado ${ }^{6}$.

\footnotetext{
${ }^{4}$ Leg. 537-1. Protocolos de José Antonio Mouriño. Año 1772. Fol. 124. AHP de L.

${ }^{5}$ Ibidem, fol. 123.

${ }^{6}$ Ibidem, fol. $124 \mathrm{v}$.
} 
El Cabildo fabricaría a sus expensas la fachada de la casa terrena igual a la que iban hacer, con una altura determinada por la solera del balcón que había en la parte posterior de la casa habitada por el abogado. Las paredes tendrían la seguidad suficiente para poder continuar la obra con la misma altura que la existente. Si no quería darle más elevación, el Cabildo tenía que dársela cubierta y losada, pero si la alzaba, sería por su cuenta toda la obra que hiciese desde la solera del balcón.

El corral posterior, que servía para las dos casas, sería separado por el Cabildo con una pared de once o doce cuartas de alto. Dejarían cinco cuartas y media de hueco entre ella y la cocina de la casa de don Pedro, por la parte que confinaba por la huerta, para un pozo, haciendo lo mismo el Cabildo en el que le quedaba o en la huerta.

Si quisiesen hacer una casa en la huerta, la podía construir levantando la pared desde la esquina de la cocina tirando línea recta por la huerta del Cabildo a la esquina de la casa que éste ha fabricado en la cabecera de ella, para la viuda de José González Sierra ${ }^{7}$, y su pared con el mismo grueso que esta tiene..., pero con tal que en las habitaciones bajas no ha de poder hacer ni fabricar dicho don Pedro ventana alguna rasgada, sino tragaluz, o lumiera con su reja de hierro de modo que no quepa la cabeza de un hombre ${ }^{8}$.

Tres años después estaban concluídas dos de las casas y otras dos en su estructura y cubiertas, deduciéndose que había otras en construcción. Una de las terminadas fue alquilada por el canónigo fabricario don Mauro Valladares, al flamenco Carlos Wassermayer, comerciante al por mayor en la ciudad de Lugo, que se había casado con doña Teresa Feliciana Breugel Cedrón y Quiroga, hija de don Andrés Cedrón, que había sido cónsul en la corte de Londres, y de doña Feliciana de Breugel y Cedrón, residente en Santiago de Miranda en la jurisdicción de Adai.

El 5 de enero de 1776 se formaliza el contrato de arrendamiento de una casa sita en el Buen Jesús de esta ciudad, perteneciente a la fábrica de dicha santa iglesia, según que por un costado confina en otra de la misma fábrica que habita el señor prior de Acoba, y por el otro en la que lo hace el licenciado don Pedro de Neira, abogado, la cual tiene

${ }^{7}$ Fue también maestro de obras de la catedral y autor de varios edificios notables de la ciudad.

${ }^{8}$ Leg. 537-1. Cit. Fols. 124 v - 125.

"CUADERNOS DE ESTUdios GALLEGOS", Tomo XLI, Fascículo 106, Santiago 1993-94. 
un pedazo de huerta a su trasera que confina con otra del mismo don Pedro de Neira, la que le arrienda con dicha casa, que esta se halla nueva ${ }^{9}$. El arriendo se hacía por tres años, contados desde el día de San Juan de junio, por 800 reales de vellón cada año.

El día 5 de noviembre de 1775 el deán don Luis de Angostina y el arcediano de Neira, don Antonio Cosentino de Tejada, que habían sido comisionados por el Cabildo para el remate de la obra de carpintería de las casas que se han hecho y se están haciendo en la plazuela llamada del Buen Jesús, hacen la adjudicación formal que había tenido lugar el día 21 de octubre, siendo el plazo de ejecución de siete meses.

La importancia de la obra hace que formen compañía nueve carpinteros de la ciudad. La postura más ventajosa fue la de 8.000 reales de vellón, con la condición de que les diesen todo el material necesario a pie de obra, serrada la madera y pinazos que fuesen necesarios para los tabiques, que estos, puertas y ventanas, tragaluces y demás obra de carpintería, lo habían de ejecutar en los sitios que señalan los planos que se les han manifestado y entregado, firmados de dicho señor comisionado y del maestro don José Elexalde ${ }^{10}$.

A través de las condiciones podemos enterarnos de algunas innovaciones constructivas. Así, las puertas de lo que llaman suelos, o planta baja, de las dos casas, serían de telar, con molduras iguales a las que se han hecho y están haciendo en las casas en que viven prior de Acoba y Delgado, $y$ de una hoja, excepto aquellas que le parecieren convenientes a dicho señor arcediano comisionado, el que vayan de dos, en lo que no se ha de poner repugnancia alguna" ${ }^{11}$.

Las puertas principales de la fachada también tenían que ser iguales a las de las casas del prior y de don Francisco Gil Delgado, de tres hojas, una entera y la otra dividida en dos. Este sistema tradicional en nuestras construcciones, permite mantener abierta la hoja superior para ventilación e iluminación del portal, impidiendo la inferior la entrada de animales. Los tragaluces, o ventanas correspondientes al cuerpo situado entre el bajo y el alto, serían de dos hojas cada uno con su entrepaño.

Las puertas de los pisos altos serían también de hechura de telar, con sus tablas recortadas y molduras conforme a las de las citadas casas

\footnotetext{
${ }^{9}$ Leg. 539-1. Protocolos de José Antonio Mouriño Varela. Año 1776. Fol. 16.

${ }^{10}$ Leg. 538-2. Protocolos de José Antonio Mouriño Varela. Año 1775. Fol. 379.

"Ibidem, fols. 379-379 v.
} 
que habitan dichos señores prior y Delgado, unas de una hoja y otras de dos, según se les dispusiere por dicho comisionado, o por la persona del arte que está nombrada para el reconocimiento, dirección y seguridad de la obra ${ }^{12}$. Cada hoja llevaría cinco entrepaños. Las puertas y contrapuertas de las ventanas rasgadas, así como las otras, también tenían que ser iguales a las de las casas ya citadas.

En los primeros pisos la hechura sería tosca por abajo y por arriba bien juntas y rehundidas. En los segundos sería de hechura limpia y bien unidas y asentadas, y en los terceros o fayados, serían como los segundos, excepto que en donde fuesen los cielos rasos, no irían limpias, pero sí bien juntas y asentadas.

Aparece una entreplanta, de menor altura, entre la planta baja y la más alta, que sería la principal. Nos recuerda a las existentes en los palacios barrocos destinadas a la servidumbre. Los vanos de ella no son rasgados, por tanto disponen de menos luz, y el acabado de la carpintería es, como hemos visto, más tosco.

Se utiliza el cielo raso, como podemos comprobar por la documentación, en lugar del artesonado de madera, pues se señala que se harían en las salas y gabinetes del segundo alto por la parte de adelante que dice a la fachada, en ambas casas, y han de quedar concluídos en la próxima disposición para darles cal ${ }^{13}$.

Cada una de las casas llevaría dos escaleras, una principal, con sus balaustres de madera recortados y barandillas, y la otra para los fayados.

Los tabiques para las separaciones, se colocarían según los planos, quedando apinazados en sus pinazas, asentadas y clavadas, con marcaciones y guarniciones, y con las puertas asentadas en donde le correspondiese.

Las puertas y ventanas quedarían también asentadas con su herraje, excepto aquellas que fuesen en cantería, no siendo de su cuenta el sentarla ni emplomarla en ella por ser este oficio propio de canteros y no del suyo $^{14}$.

\footnotetext{
${ }^{12}$ Ibidem, fol. $379 \mathrm{v}$.

${ }^{13}$ Ibidem.

${ }^{14}$ Ibidem, fol. 380 .
} 


\section{LA PLAZA}

Aunque la ciudad es de fundación romana, su trama urbana nada tiene que ver con el trazado regular e hipodámico de sus vías que, ocultas en la actualidad bajo el suelo, conocemos cada vez mejor gracias a las excavaciones arqueológicas. Hay una marcada dependencia del organicismo medieval que da lugar a manzanas poligonales determinantes de una laberíntica red de calles caracterizadas por su angostura en cuyo encuentro el espacio se dilata, configurando pequeñas plazas, triangulares, o cuadrangulares, según sean tres o más el número de vías que confluyen. Su función es exclusiva de envase, muy distinta, por tanto, de aquellas otras que por su superficie y existencia de edificios civiles o religiosos importantes, van a condicionar su actividad.

A diferencia de lo que ocurrió con otras plazas mayores de ciudades españolas, cuya principal característica es la uniformidad de las edificaciones, en la de Lugo lo va a ser precisamente su diversidad, tanto desde el punto de vista arquitectónico como funcional. Por ello, la Plaza del Buen Jesús supondrá una novedad dentro del conjunto urbano lucense al presentarnos, por una parte una arquitectura nueva, en la que prevalece visualmente la uniformidad, pero concebida con criterios de comodidad, y por otra una distribución del espacio comunitario pensado para uso y disfrute del público.

Hay un fondo arquitectónico principal, constituído por la fachada de la catedral, y dos secundarios a ambos lados, que definen la uniformidad de las construcciones civiles. Son las nuevas casas construídas por el Cabildo y otros particulares.

La nueva plaza se conformó entre 1770 y 1788 . Hubo una primera fase arquitectónica, debida a José de Elexalde, en la que se construyen los edificios del lado $\mathbf{N}$, y otra urbanística, una vez terminada la fachada de la catedral, a cargo de Miguel Ferro Caaveiro y el aparejador Alexos Frieiro, que se desarrolla entre 1785 y 1788 . Por lo que se refiere a los pertenecientes a la catedral, se hicieron entre 1770 y 1776. Los del lado $S$, fueron posteriores.

Situada en la parte $\mathbf{S W}$ del recinto amurallado, entre la fachada principal de la catedral y la muralla, en ella desembocan cinco calles: por el $\mathbf{W}$ la calle Falcón, acceso a la muralla, posiblemente por una de las antiguas escaleras de doble ala, no por rampa, y puerta do Pexigo, por el $\mathbf{S}$ la calle de los Clérigos, y por el $\mathbf{E}$ la actual del Buen Jesús y por el $\mathbf{N}$ la de la Catedral. 
Su aspecto, antes de la modificación, era extremadamente austero, pero de mayor superficie dado que la nueva fachada se adelantó incluyendo en la catedral parte del viejo atrio. La sobriedad de la fachada románica y la pobreza de las pequeñas edificaciones existentes en sus lados $\mathbf{S}$ y $\mathbf{N}$, aconsejó al Cabildo su cambio una vez concluida la obra de la nueva, a la que aparecen vinculados los nombres de Carlos Lemaur, Julián Sánchez Bort, José de Elexalde, Miguel Ferro Caaveiro y ya en el siglo XIX, Nemesio Cobreros. El estilo es un neobarroco romano no ajeno a la influencia de Ventura Rodríguez ${ }^{15}$.

El 19 de noviembre de 1785, el Cabildo escribe al Ayuntamiento para comunicarle que una vez terminada la obra de la fachada principal de la catedral, en correspondencia a la suntuosidad de aquella, le parece preciso formar un atrio en lugar y remplazo del que antes había, aunque con algo más de extensión y magnificencia para cuya obra era necesario algún terreno más ${ }^{16}$. Recordemos que una de las torres quedó en la mitad del primer cuerpo y la otra sin hacer.

Como no se quería perjudicar al público con esta construcción, la corporación eclesiástica había acordado exigir la aprobación de la Ciudad y que esta nombrase a dos capitulares que con el arcediano de Neira y don Andrés de Prado, lo arreglasen y dispusiesen de la mejor forma.

En la contestación que da el Ayuntamiento, se hace ver que se había alargado la nave mayor, adelantando la fachada, pues señalan que es muy notoria la extensión que se ha hecho en la fachada de la Santa Iglesia de la que antes tenía, y por lo mismo aún cuando en aquel entonces tuviese atrio capaz, en el día se hacía muy dificultosa esta nueva obra por la estrechez en que había dejado constituído el paso público aquella, lo cual no sólo no es reparable, pero se aumentará infinito siempre que se condescienda en esta solicitud ${ }^{17}$.

A pesar de ello, la Ciudad deseaba corresponder con la buena y antigua relación que siempre había profesado al deán y Cabildo en términos que fuesen compatibles con el bien público, nombrando a don Cayetano Felipe Gil y a don Ramón Noguerol, para que en presencia del procurador general, al que incumbía reclamar cualquier perjuicio que se causase

\footnotetext{
${ }^{15}$ Sobre esta cuestión ver: Chueca Goitia, F. Ventura Rodríguez y la escuela barroca romana. Archivo de Arte Español. Núm. 52. Madrid, 1942.

${ }^{16}$ Leg. 110. Actas capitulares de 1785. Consistorio 19-11. AHP de L.A.

${ }^{17}$ Ibidem.
} 
al público, pudiesen acordar con los diputados del Cabildo, el mejor medio y método de la nueva construcción de forma que no se perjudicase la utilidad pública dejando imposibilitado el paso, principalmente en un sitio tan circunstanciado como lo es el adonde intenta hacerse dicha obra, y que sirve de una de las entradas más públicas y frecuentadas del pueblo ${ }^{18}$.

La negociación para tratar sobre la extensión que debía tener el nuevo atrio se demoró varios meses, dando cuenta de ella en el consistorio del día 12 de julio de 1786. Se vuelve a insistir en que habían introducido el atrio dentro de la Santa Iglesia, con la obra que hicieron de naves y fachada, la mayor parte del que antes tenían ${ }^{19}$.

Personados los comisionados en el lugar donde se había de traer la innovación, aunque sin la presencia del procurador general, concurrió el maestro que dirigió la propia obra Alexos Frieiro, que presentó un plan manifestando lo que el nuevo atrio debía tener de largo y ancho, con expresión de sus cantidades y dimensiones, para el desahogo de la entrada pública y salida al camino real que camina a las ciudades de Santiago y Orense y otras partes ${ }^{20}$.

Para hacer más capaz la plazuela o atrio era preciso coger terreno público allanando y terraplenando el pedazo de muralla que está a la entrada de la puerta del Postigo y a su mano izquierda, siguiendo hasta la esquina de la casa de don Pedro Pablo Montenegro, dueño de la de Rego de Ameneiro. Para compensar el terreno público que se cogía, los comisionados del Cabildo se comprometían a tratar con él la cesión de un pedazo de terreno que tenía destinado a huertå y practicar una subida cómoda para la muralla por aquella situación ${ }^{21}$.

En el plano de la plazuela, que se conserva en el archivo de la catedral $^{22}$, Ferro Caaveiro señala con las letras AB la fachada nueva de la catedral. EF las casas del lado $\mathbf{S}$ pertenecientes al Cabildo y con $\mathbf{C D}$ las del lado $\mathbf{N}$, en las que, según la leyenda del plano, residían el deán, algunos capitulares y particulares. Las letras OP delimitan el cierre del atrio

\footnotetext{
${ }^{18}$ Ibidem.

${ }^{19}$ Ibidem. Consistorio 12-07

${ }^{20}$ Ibidem.

${ }^{21}$ Ibidem.

${ }^{22}$ Incluido por García Alcañiz Yuste, Julia en Arquitectura del Neoclasicismo en Galicia. Barcelona, 1989, p. 151.
}

"CUADERNOS DE ESTUDIOS GALLEGOS", Tomo XLI, Fascículo 106, Santiago 1993-94. 
que se aprovecha por el interior como banco, al que se accede por tres entradas, una situada en el centro, a eje con la fachada, y dos laterales, inmediatas a ella. El encuentro de los muros en el ángulo se suaviza con una curva. GH es la casa y jardín de un particular. $\mathbf{J}$ la casa inmediata a la muralla. L la entrada en la ciudad eliminando la puerta de Santiago o del Pexigo. $\mathbf{M}$ cubo de la muralla que se derribada. $\mathbf{N}$ adarve de la muralla. QR, terreno que pertenecía a don Pedro Pablo Montenegro que el Cabildo pretendía recuperar para el tránsito por considerar que se había usurpado al público.

Los comisionados del Ayuntamiento no aceptaron la propuesta por entender que era extraña del honor y religiosidad en que se hallaban constituídos por no corresponder con lo que habían acordado. Según ellos, el Cabildo había aprovechado sus ausencias de la ciudad para quitar al público todo el terreno que tenían en aquella situación, dejándole tan solamente una reducida calle para su entrada y salida sin haber cumplido con deshacer, ni allanar el murallón y citada huerta por mantenerse en el mismo estado que antes tenía, verificándose de esta omisión lo contratado por unos y otros diputados, perjudicando con ello las franquicias del público y menospreciando el respetable cuerpo de la Ciudad como representado por sus diputados ${ }^{23}$.

$\mathrm{Al}$ regresar y observar la falta de legalidad en lo contratado, procuraron subsanar los defectos con los diputados del Cabildo, mediante carta que escribieron el día 5 de julio, pero no fueron atendidos, más bien divulgaron que lo que estaba hecho subsistiría. Personados en el lugar, trataron de nuevo sobre el asunto.

El día 12, contestó el Cabildo por escrito indicando que por los informes que ha dado y nuevas medidas que ha tomado el maestro, a cuyo cargo y dirección estuvo y corrió la obra del expresado atrio, se ha reconocido que está tan distante de hallarse exceso en la extensión de este a lo que comprende el plan que se les puso presente a VSS a el tiempo de nuestra armoniosa verbal contrata, que aún le falta más de vara y media del terreno que, según aquel, había de ocupar, y por consiguiente quedado este ensanche más a la calle, de manera que caben por ella muy bien tres carros a la par aunque sean cargados ${ }^{24}$.

Señalaban que se habían puesto en contacto con el propietario de la

\footnotetext{
${ }^{23}$ Ibidem.

${ }^{24}$ Ibidem. Anexo.
}

"CUADERNOS DE ESTUdiOS GALLEGOS", Tomo XLI, Fascículo 106, Santiago 1993-94. 
huerta para que permitiese tirar la pared línea recta, ofreciéndole doble cantidad de dinero del que valía el terreno necesario para dicho fin, a pesar de que no se le debía considerar dueño de él, pues creían que la misma figura que hoy tiene la expresada pared manifiesta bien haber sido usurpado al público.

La cantidad que pedía la consideraban exagerada, no pudiendo hacerle frente $\sin$ gravísimo gravamen y escrúpulo de conciencia. Tampoco tenían facultades para obligarle a cederlo por un precio justo, de acuerdo con la tasación que hiciesen sujetos inteligentes, encargando esta gestión al Ayuntamiento, al tiempo que le manifestaba su interés en el mayor beneficio y comodidad del público y en las cumplidas satisfacciones de una comunidad a quien tanto amaba, respetaba y apreciaba. El Ayuntamiento tomó decisión el día 24, en el sentido de pasar oficio al Cabildo para que procediese al cumplimiento de lo acordado, pues de lo contrario usaría de los recursos de su competencia.

E1 29 de julio de 1786, el Cabildo escribe al Ayuntamiento, acusando recibo de la carta enviada el día 24, para conferenciar sobre la forma con que se debía hacer el atrio de esta santa iglesia, de modo que el público no quedase perjudicado ${ }^{25}$.

Señalaban que no podían contestar en el día con la claridad e inteligencia que requería el asunto por estar ausente uno de los comisionados, facultado par que se zanjase cualquier dificultad.

El día 9 de agosto, escribía de nuevo el Cabildo. No le dieron contestación por la falta de cumplimiento de lo pactado. Les comunicaban que se había incorporado uno de sus diputados, y que con su compañero le había hecho presente las insinuaciones que contenía la carta de la Ciudad que no se correspondía con la realidad de lo ocurrido, padeciéndose algunas equivocaciones tanto en dichos como en hechos.

Ante la imposibilidad de dar respuesta y la satisfacción que merecía su oficio, encontraban como mejor y más proporcionado medio para evitar toda desavenencia y lograr la pacificación, que los mismos capitulares comisionados conferenciasen sobre lo ocurrido y dispusiesen lo más conveniente al servicio de Dios y del público.

El Ayuntamiento acordó que sus comisionados deshiciesen todas las equivocaciones para evitar disputas, dando cuenta a la Ciudad, la cual les ampliaría las facultades para hacer cualquier transacción.

\footnotetext{
${ }^{25}$ Leg. 111. Actas capitulares de 1786. Anexo consistorio 5-08. AHP de L.A.
} 
El día 12 de octubre don Pedro Pablo Montenegro Rois y Rivadeneira, dueño del terreno que se pretendía incorporar a la plaza, escribía a los comisionados del Cabildo, haciendo referencia a la conversación que habían mantenido en la primavera. Le habían ofrecido 100 ducados, así como el derribo y reconstrucción del nuevo muro. El propietario pretendía que éste se hiciese con la cimentación suficiente para poder construir una casa. A esta pretensión no le habían contestado.

El Cabildo dio respuesta el día 19, accediendo a su propuesta. El nuevo muro se haría tirándole en línea recta por los dentellones que salen de la pared del cuarto de la misma contígua a la subida de la mura$\mathrm{Ila}^{26}$.

Alguna de las condiciones que imponía se excedía de las competencias de la corporación catedralicia, 'como el poder hacer casa con ventanas rasgadas y balcones, una cuestión urbanística dependiente de la Ciudad. A pesar de ello no tenían inconveniente en que figurase en escritura pública, siempre que no ocupase más terreno que el que iba a quedar.

Pero surgen nuevos inconvenientes que van a impedir la formalización del convenio y la terminación de la obra. La casa y la huerta estaban arrendadas por seis años al coronel don Pedro Luis de Ulloa, habiendo concluido el contrato en 1783 sin que la dejase libre, lo que dio lugar a un pleito que se resolvió en 1788 a favor del propietario.

El 21 de junio se formaliza el acuerdo ante el escribano José Antonio Mouriño, lo que permitió terminar la obra. Hay un recibo con fecha del 2 de julio de 1788 por importe de 1.000 reales recibidos por el Ayuntamiento por componer y arreglar el montón de tierra y murallón que dice al frente de dicho atrio y se halla pegado a la muralla unida a la puerta del Postigo ${ }^{27}$.

\footnotetext{
${ }^{26}$ Leg. 29. AC de L.

${ }^{27}$ Ibidem.
} 


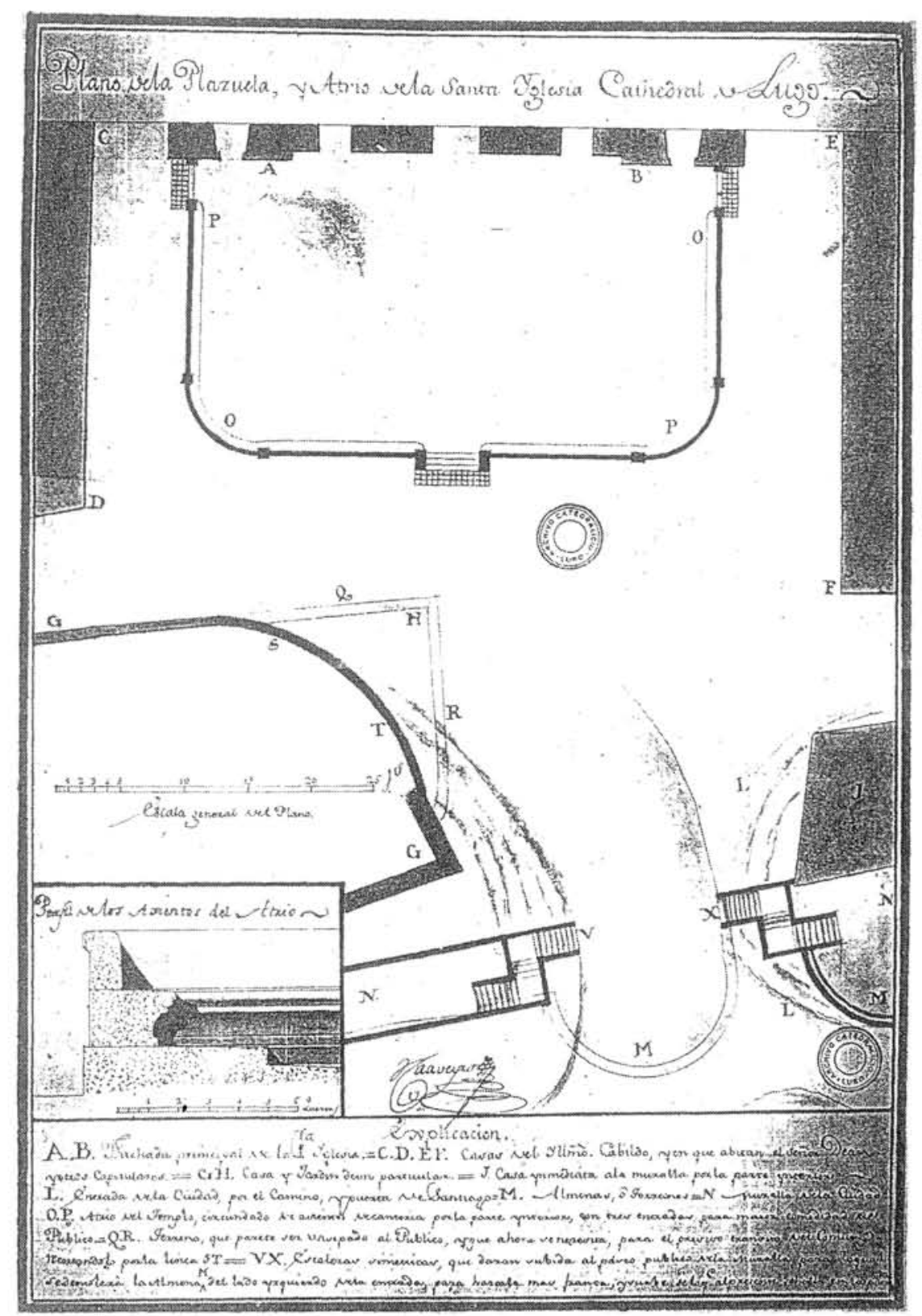

Proyecto de la plaza del Buen Jesús, realizado por Miguel Ferro Caaveiro $\mathrm{y}$ ejecutado por Alexos Frieiro. 
En el proyecto de Miguel Ferro Caaveiro se preveía la eliminación del cubo izquierdo y de la puerta del Pexigo.
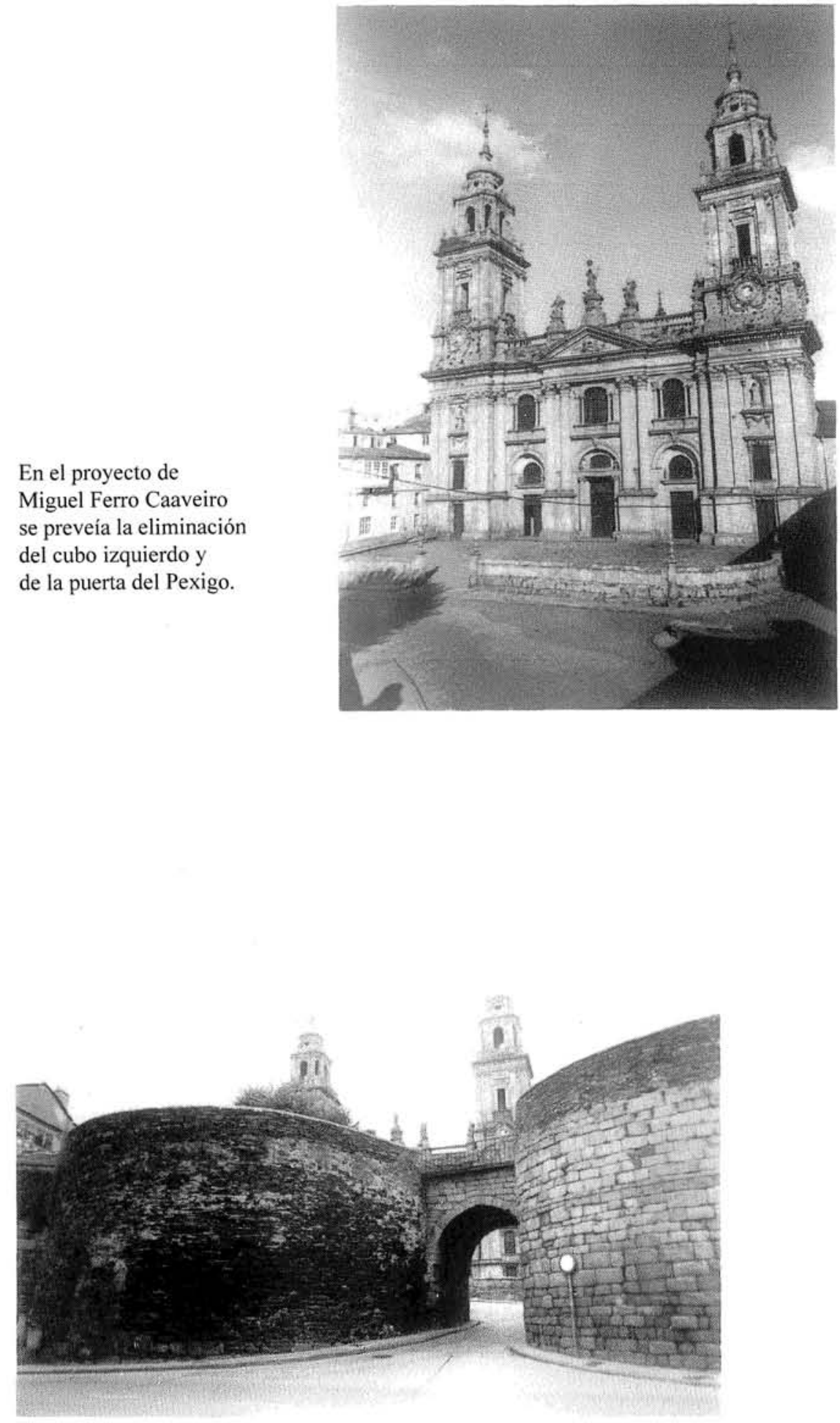

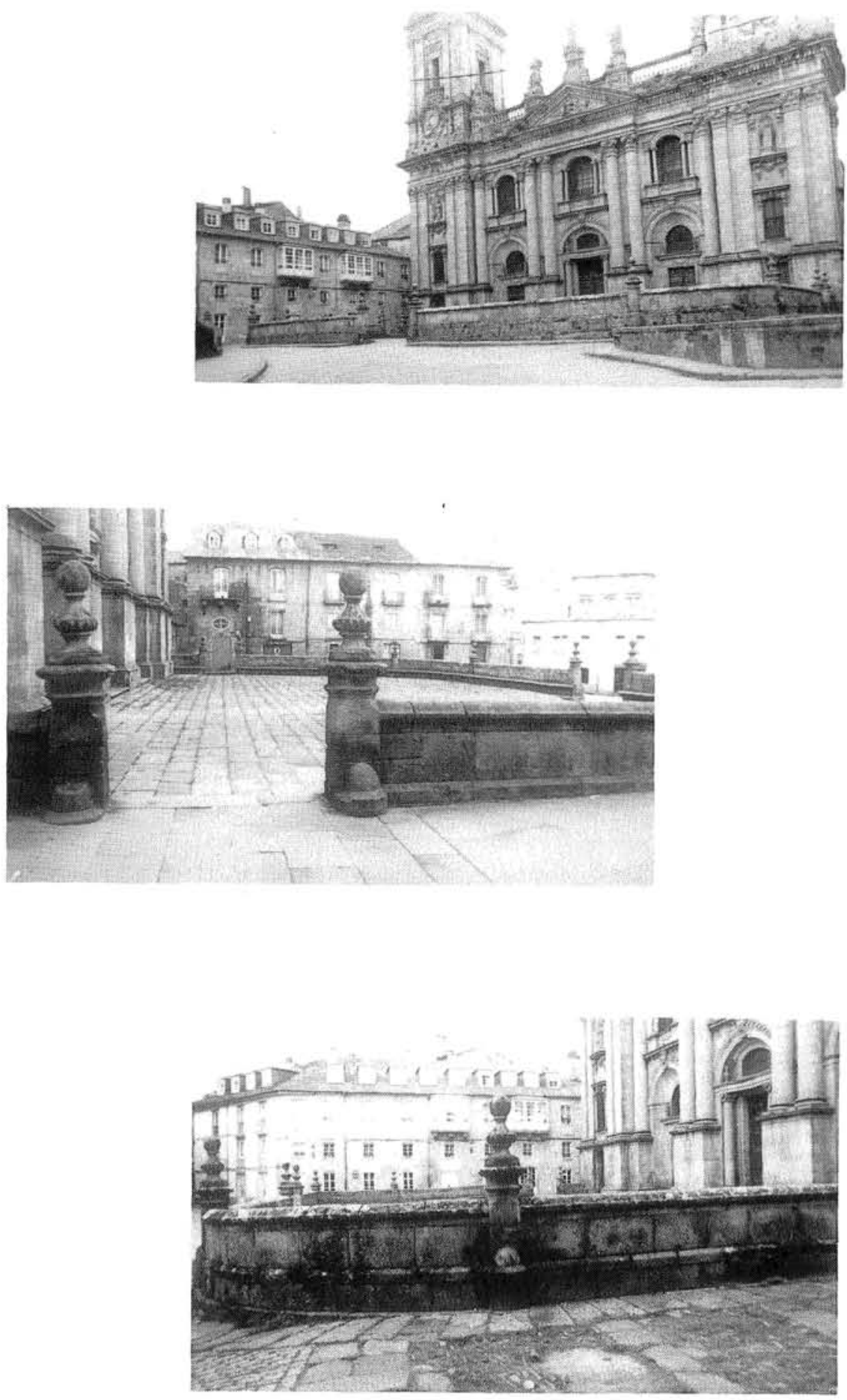

Tres aspectos de la plaza neoclásica del Buen Jesús de Lugo, la primera obra del urbanismo moderno de la ciudad. 


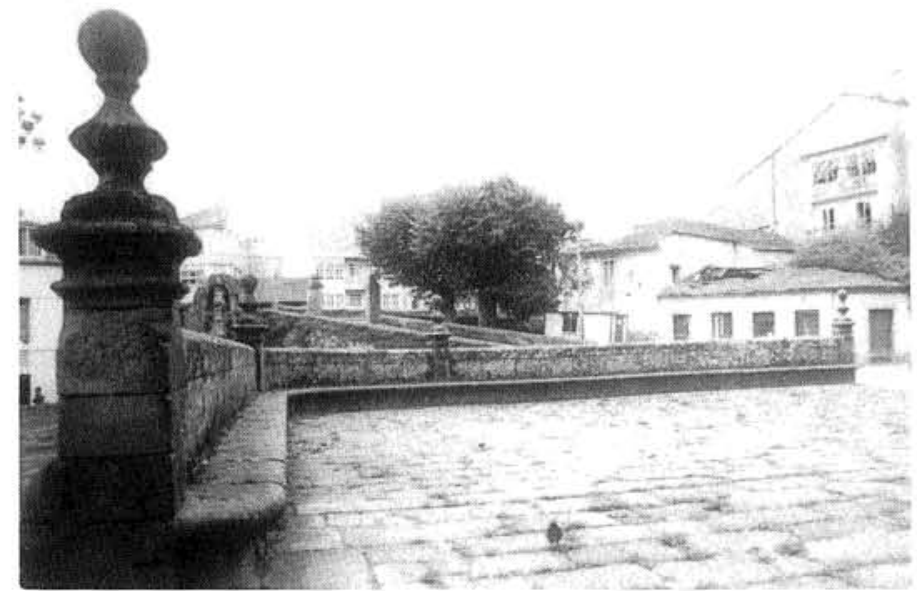

Vista parcial del atrio con el banco interior al muro de delimitación del espacio reservado al público.

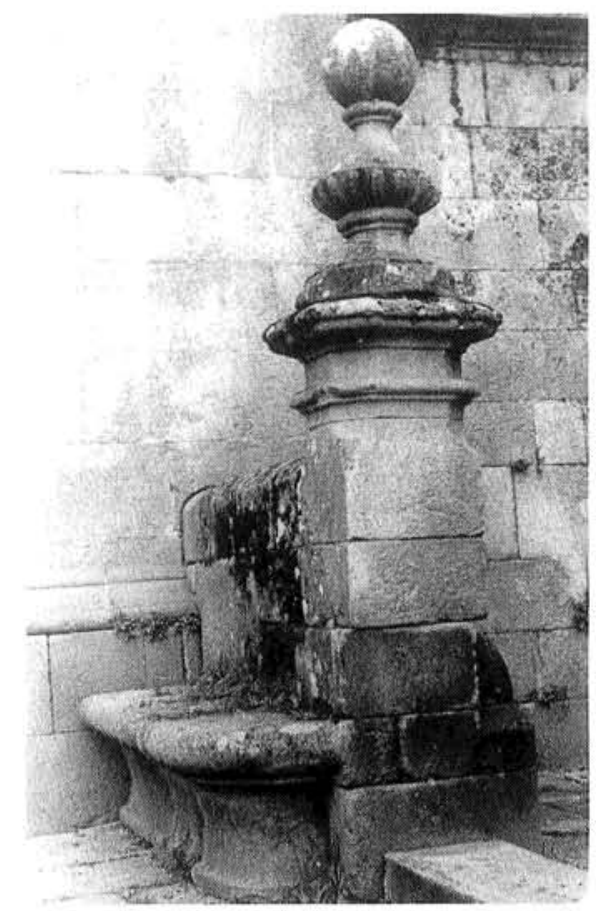



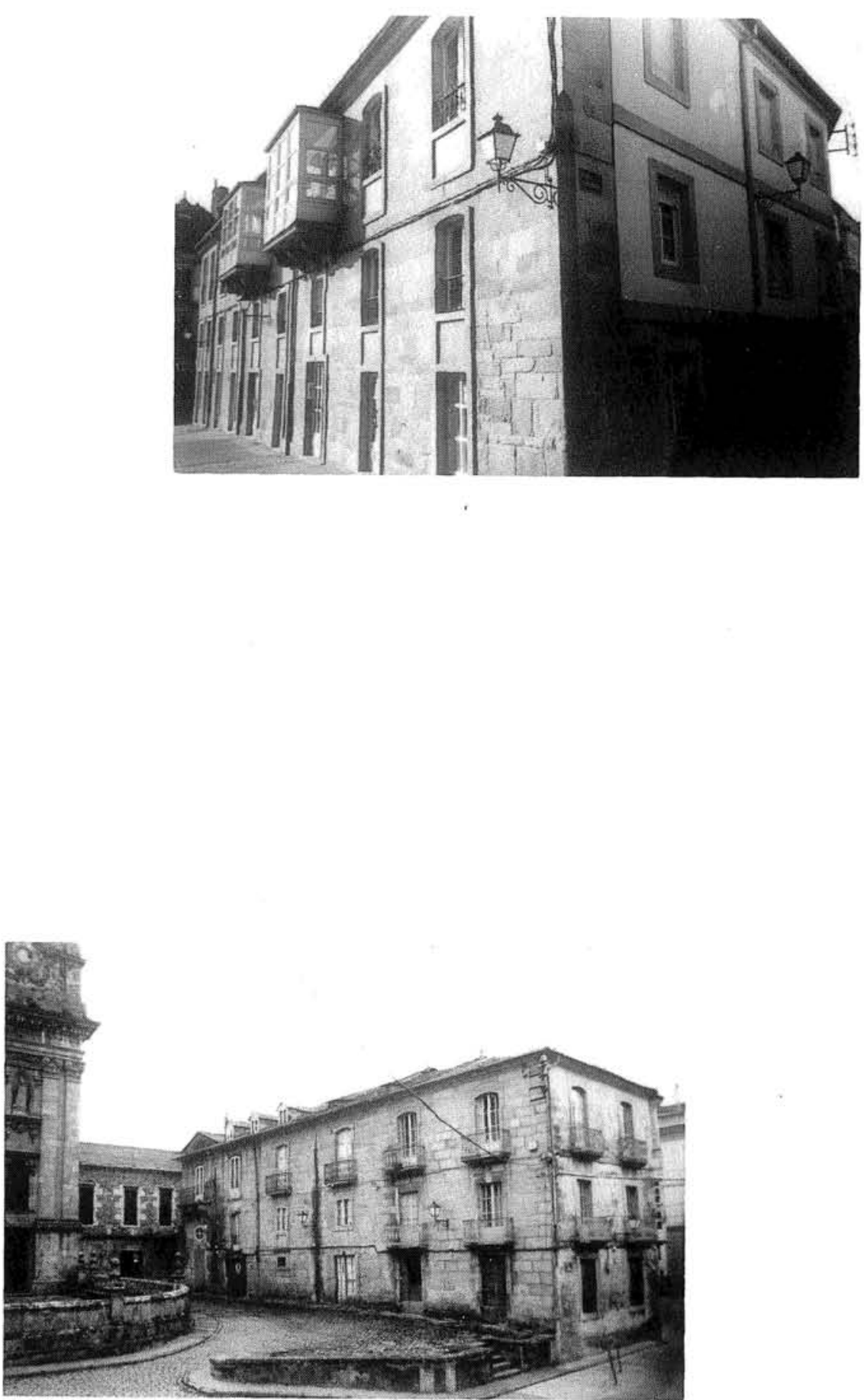

Arriba casas del deán, del prior de Acoba y de don Pedro Antonio de Neira, situadas en el lado $\mathrm{N}$ de la plaza. Abajo, casas de particulares en el lado $\mathrm{S}$. 

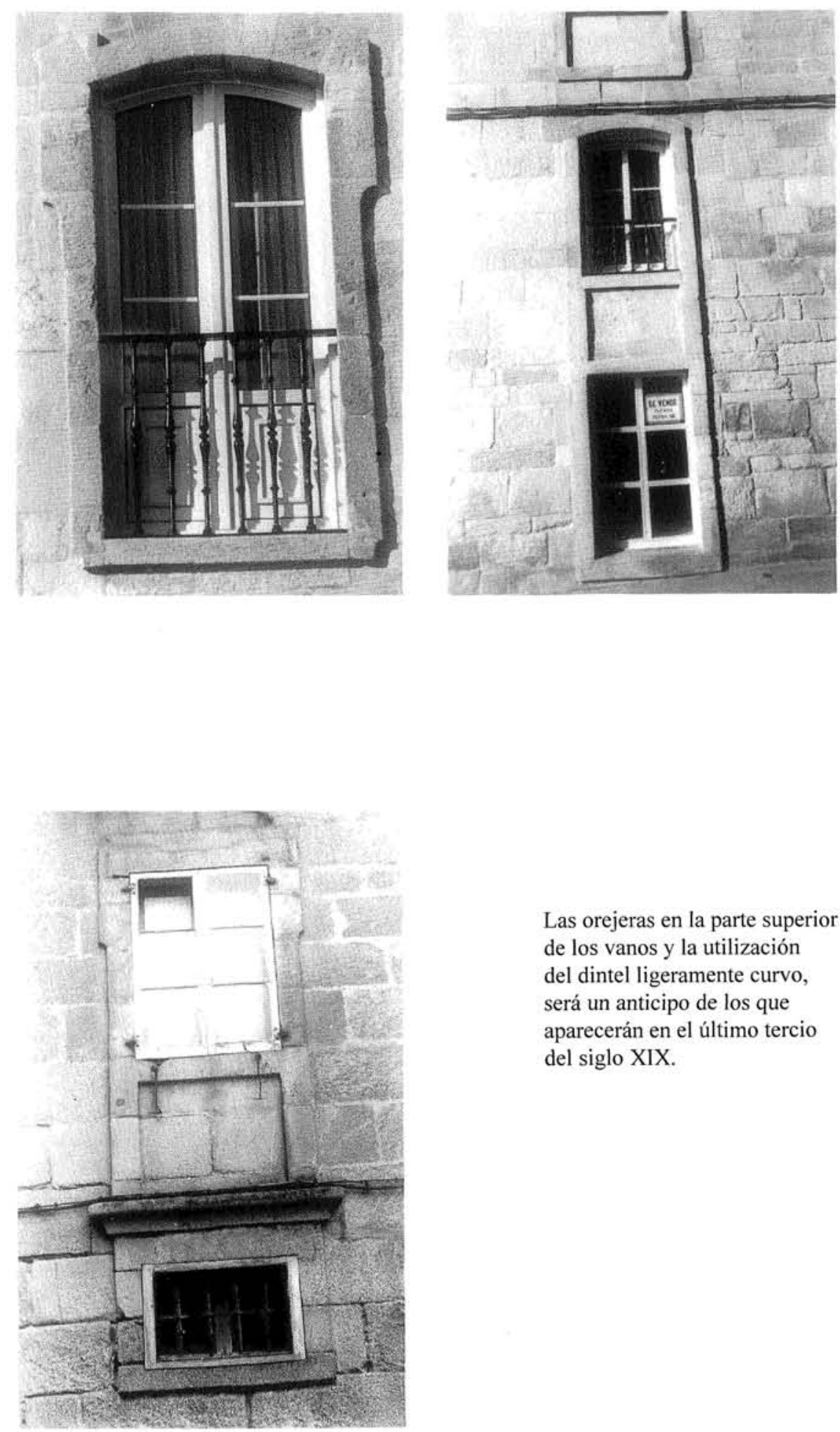

Las orejeras en la parte superior de los vanos y la utilización del dintel ligeramente curvo, será un anticipo de los que aparecerán en el último tercio del siglo XIX. 


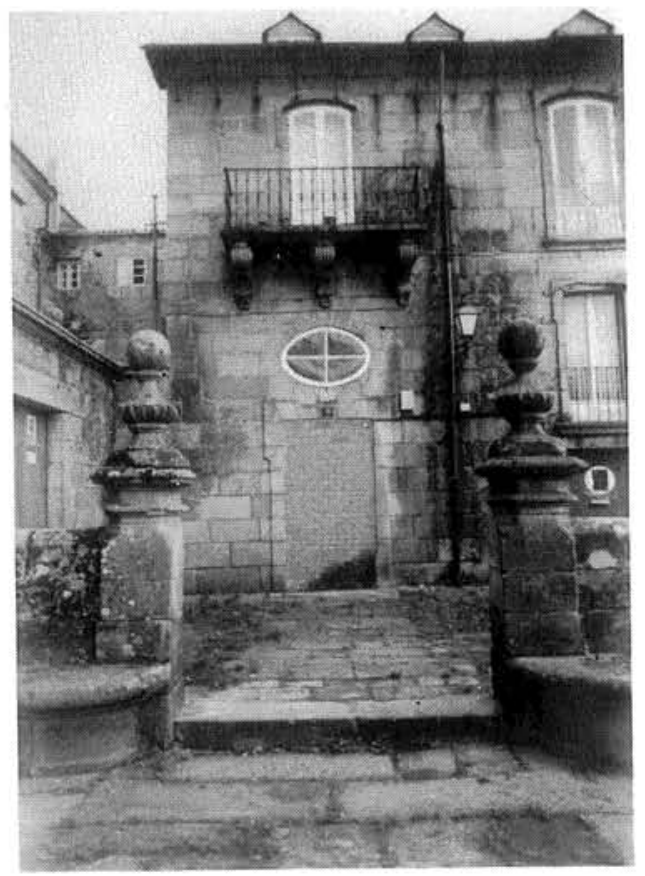

Los elementos barrocos perviven en los edificios de la plaza del Buen Jesús, especialmente en los balcones volados y sus ménsulas.
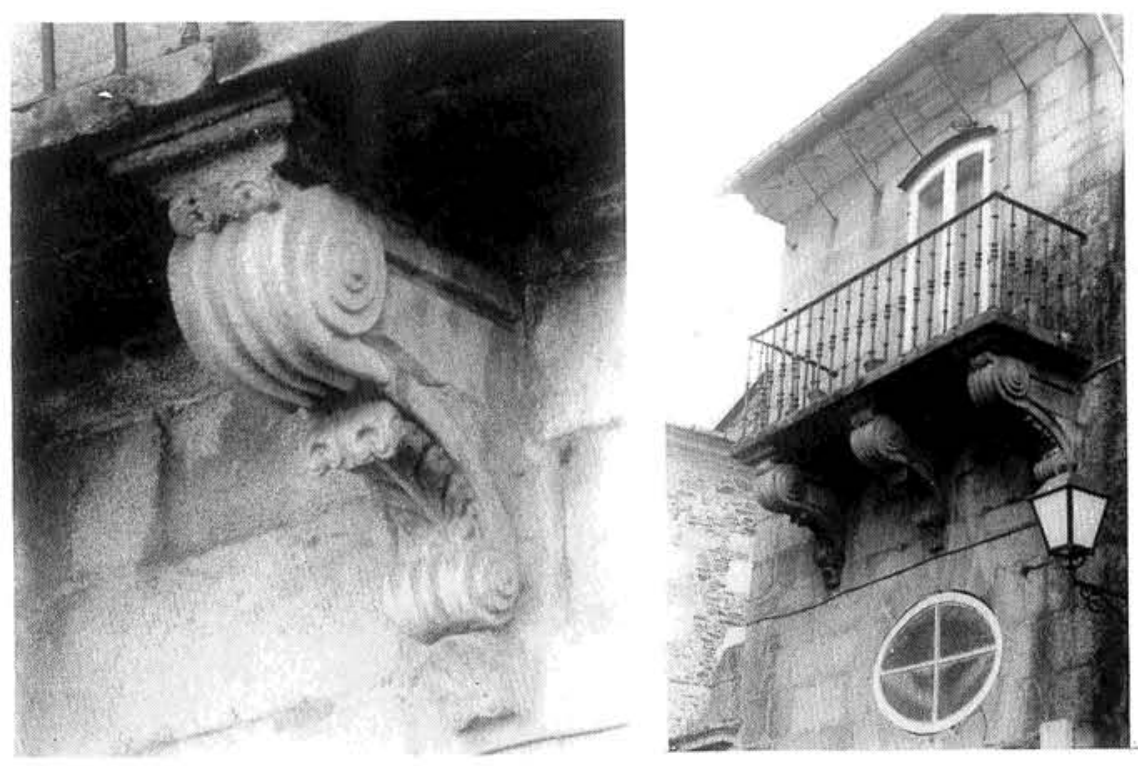